1. MBBS, M.Phil

Associate Professor Pharmacology Suleman Roshan Medical College, Tando Adam, Sindh, Pakistan.

2. MBBS, M.Phil

Assistant Professor Biochemistry Khairpur Medical College,

Khairpur Mirs, Sindh, Pakistan

3. MBBS, M.Phil

Assistant Professor Biochemistry

Suleman Roshan Medical College

Tando Adam, Sindh, Pakistan.

4. MBBS, M.Phil

Assistant Professor Physiology

Khairpur Medical College,

Khairpur Mirs, Sindh, Pakistan.

5. MBBS, M. Phil

Assistant Professor Hematology

Indus Medical College

Tando Muhammad Khan, Sindh, Pakistan.

6. MBBS, M.Phil

Assistant Professor Pathology

Indus Medical College

Tando Muhammad Khan, Sindh, Pakistan.

7. MBBS, M.Phil, FCPS

Associate Professor Faculty of

Medicine and

Allied Medical Sciences

Isra University, Hyderabad, Sindh,

Pakistan.

Correspondence Address:

Dr. Kashif Rasheed Shaikh

Department of Pharmacology

Suleman Roshan Medical College,

Tando Adam, Sindh, Pakistan.

mailboxKxm@gmail.com

Article received on:

28/04/2020

Accepted for publication:

02/06/2020

\section{Vitamin Cobalamin deficiency in macrocytic anemia reporting at a Tertiary Care Hospital.}

Kashif Rasheed Shaikh ${ }^{1}$, Shumaila Shaikh², Sadia Tabassum ${ }^{3}$, Shagufta Memon ${ }^{4}$, Umair Ali Soomro ${ }^{5}$, Shomail Saeed Siddiqui ${ }^{6}$, Haji Khan Khoharo ${ }^{7}$

ABSTRACT... Objective: Determine the frequency of vitamin cobalamin deficiency in macrocytic anemia cases reporting at tertiary care hospital. Study Design: Cross Sectional study. Setting: Faculty of Medicine and Allied Medical Sciences, Isra University, Hyderabad, Sindh Pakistan. Period: January 2017 to October 2018. Material \& Methods: 450 cases of both genders, diagnosed as macrocytic- megaloblastic anemia were studied for the vitamin Cobalamin levels. Cases were collected through non- probability convenient sampling by inclusion and exclusion criteria. Consenting volunteers were asked for blood sampling. $5 \mathrm{~mL}$ blood was taken from ante - cubital fossa. Samples were centrifuged and sera were collected for the estimation of vitamin cobalamin by ELISA - assay kit. Continuous and categorical variables were entered in SPSS (version 21.0) and analyzed by Student t-test and Chi-square test respectively at $95 \% \mathrm{Cl}(\mathrm{P} \leq$ 0.05). Results: Male and female comprised 225 (43.3\%) and 294 (56.6\%) of 519 subjects. Male to female ratio was noted 1.30:1. $\mathrm{MCV}, \mathrm{MCH}$ and $\mathrm{MCHC}$ show statistically significant difference between male and female $(\mathrm{P}<0.05)$. MCV in male was $96.8 \pm 9.92 \mathrm{fl}$ vs. $105.5 \pm 12.04 \mathrm{fl}$ in female $(P=0.0001)$. Normal cobalamin was noted in $15.2 \%(n=79)$ and any type of cobalamin deficiency was noted in $84.7 \%(n=440)(P=0.0001)$. Conclusion: The present study reports frequency of $84.7 \%$ Cobalamin deficiency in macrocytic anemia reporting at Indus Medical College Hospital. Further studies are recommended by the treating physicians.

Key words: $\quad$ Cobalamin Deficiency, Macrocytic Anemia, RBC Indices.

Article Citation: Shaikh KR, Shaikh S, Tabassum S, Memon S, Soomro UA, Siddiqui SS, Khoharo HK. Vitamin Cobalamin deficiency in macrocytic anemia reporting at a Tertiary Care Hospital. Professional Med J 2021; 28(4):527-532. https://doi.org/10.29309/TPMJ/2021.28.04.4748

\section{INTRODUCTION}

Mean corpuscular volume (MCV) is a measure of red blood cell (RBC) volume. Large MCV is a clinic - hematological indicator of macrocytic anemia. RBC showing volume $\geq 100 \mathrm{fl}$ is termed as macrocyte that occurs due to the deficiency of folic acid and cobalamin. ${ }^{1,2}$ Macrocytes RBC are large in size and are hemolyzed as they pass through microcirculation whose diameter is less than these. Hemolysis is common in the sinusoids of liver and spleen. Other causes of cobalamin deficiency are; antibiotic drugs, proton pump inhibitors, chronic liver and thyroid disorder, etc. Vitamin cobalamin is an essential maturation factor for the nucleus of proliferating cells such as developing erythroblast along with folic acid. Nuclear maturation of RBC is arrested in case of cobalamin deficiency resulting in large MCV - RBC prone to hemolysis resulting in anemia clinically. ${ }^{3,4}$ As regards cobalamin deficiency, the RBC appear large in size, are hemolyzed and is termed as macrocytic- megaloblastic anemia. ${ }^{3,4}$ Cobalamin functions as one carbon - methyl donor for the nucleotides synthesis in young erythroblasts. Both folic acid and cobalamin are needed for the nuclear maturation of rapidly proliferating cells of bone marrow such as precursors of red and white blood cells. Cobalamin forms 2 co - enzymes called SAM (S- adenosyl cobalamin) and methyl-cobalamin. SAM (S- adenosyl cobalamin) is co - enzyme for the $L$ - methylmalonyl-CoA- coenzyme A mutase that catalyzes the methylmalonyl-CoA to succinyl-CoA. Methyl - cobalamin is co-enzyme for the "methionine synthetase" that catalyzes the biochemical reaction of homocysteine converted to methionine. ${ }^{4,5}$ Cobalamin deficiency is manifested earliest in the rapidly proliferating 
bone marrow before in others. Cobalamin is a water soluble vitamin. Nutritional deficiency of vitamin cobalamin is very common due to malnourishment; caused by parasite infestation, gut malabsorption, etc. Pregnancy is characterized by an increase demand of folic acid and cobalamin both; similar is the condition for the growing children. Parasite infestation, gut malabsorption, gastric achlorhydria, terminal ileum and pancreatic disorders are some causes of cobalamin deficiency. Fish tape - worm (Diphyllobothrium latum) is an intestinal parasite notoriously causing cobalamin deficiency. ${ }^{6,7}$ Prevalence of cobalamin deficiency is very high particularly in the developing countries that is under - reported. Few published studies show high prevalence of cobalamin deficiency ${ }^{5-8}$, and there is need for conducting further research. This scenario of neglect compelled to conduct the present study to evaluate the frequency of cobalamin deficiency in macrocytic anemia cases reporting at a tertiary care hospital.

\section{MATERIAL \& METHODS}

Ethical approval was taken from the ERC (Ethical review committee) Faculty of Medicine and Allied Medical Sciences, Isra University, Hyderabad, Sindh Pakistan. Study covered duration from January 2017 to October 2018. Cases were selected through non - probability convenient sampling according to inclusion and exclusion criteria. A sample of 450 cases of macrocytic anemia was calculated 'sampling for proportions' and included in study protocol. RBC showing raised mean corpuscular volume $(\mathrm{MCV}) \geq 100$ $\mathrm{fl}$, termed as macrocyte was inclusion criteria for analyzing blood cobalamin levels. Other inclusion criteria were; both male and female gender, age 20 - 50 years and hyper segmented neutrophils (>5 lobes). ${ }^{9}$ Strict vegetarians, microcytic, normocytic and normochromic RBC were exclude. Patients using proton pump inhibitors and multivitamins were strictly excluded. Liver, thyroid, lung and cardiac diseases were excluded on clinical history. Diabetics and those suffering from chronic diarrhea was exclusion. Subjects with history of meat and liver diet intake recently were also excluded. Clinical history of consenting volunteers was taken for ensuring inclusion and exclusion criteria. Volunteers were given proforma to sign for consent. Advantages and dis - advantages of study were briefed during the clinical history taking. Biodata and findings of blood testing were kept confidential and record was maintained strictly during the study duration. Volunteers were informed of no loss; no expenses of cobalamin testing and data will never ever be publicized. Medical officers were asked to help for screening the subjects. MCV $\geq 100 \mathrm{fl}$ was defined as macrocytic anemia. ${ }^{1,2}$ Diagnosis was made by consultant hematologist. Blood samples were collected under aseptic measures from ante - cubital fossa after a tourniquet was tightly tied. Ante - cubital fossa was sterilized with alcohol - swab. $5 \mathrm{ml}$ of blood sample was taken by venesection with a $5 \mathrm{ml}$ BD Disposable syringe (BD, USA). $2 \mathrm{ml}$ was centrifuged to get sera and $3 \mathrm{ml}$ was put in NaF containing tubes for complete blood counts. Sera were collected for the estimation of vitamin cobalamin by ELISA assay kit. Vitamin cobalamin levels were defined as normal $\geq 240 \mathrm{pg} / \mathrm{ml}$, borderline cobalamin deficiency - 170-240 pg/ml, cobalamin deficiency $<170 \mathrm{pg} / \mathrm{ml}$ and severe cobalamin deficiency $<100 \mathrm{pg} / \mathrm{ml}^{10}$ Continuous and categorical variables were entered in SPSS (version 21.0) and analyzed by Student t-test and Chi-square test respectively at $95 \% \mathrm{Cl}(\mathrm{P} \leq 0.05)$.

\section{RESULTS}

Male and female comprised 225 (43.3\%) and 294 (56.6\%) of 519 subjects $(P=0.9)$ (Table-l and Figure-1). Age (mean \pm SD) of male and female was $47.5 \pm 8.06$ and $46.7 \pm 7.93$ years respectively $(\mathrm{P}=0.30)$. Male to female ratio was noted 1.30:1. Hemoglobin and Hct (\%) shows statistical difference between male and female gender $(P=0.0001)$. Male and female shows hemoglobin and Hct (\%) 13.42 \pm 1.37 and $11.5 \pm 1.07 \mathrm{~g} /$ dl $(\mathrm{P}=0.0001) \quad \& \quad 43.0 \pm 6.07$ and $36.1 \pm 3.81 \%$ $(P=0.047)$ respectively. $\mathrm{RBC}$ counts were noted as $3.5 \pm 1.31 \times 10^{9} / \mu \mathrm{L}$ and $3.8 \pm 1.35 \times 10^{9} / \mu \mathrm{L}$ in male and female respectively. MCV, $\mathrm{MCH}$ and $\mathrm{MCHC}$ show statistically significant difference between male and female $(\mathrm{P}<0.05)$ (Table-I). MCV in male was $96.8 \pm 9.92 \mathrm{fl}$ vs. $105.5 \pm 12.04 \mathrm{fl}$ in female $(P=0.0001)$. Serum Cobalamin level in female was low $187.1 \pm 73.41 \mathrm{pg} / \mathrm{ml}$ compared to $245.3 \pm 63.0$ 
$\mathrm{pg} / \mathrm{ml}$ in male $(\mathrm{P}=0.0001)$ (Table-l). Table-Il shows the mean +/- SD cobalamin levels in total study subjects. Table-III shows the frequency of cobalamin level - normal, borderline, deficiency and severe deficiency in male and female subjects. Normal cobalamin was noted in $15.2 \%$ $(n=79)$ and any type of cobalamin deficiency was noted in $84.7 \%(n=440)(P=0.0001)$.

\begin{tabular}{|l|c|c|c|}
\hline & Male $(\mathbf{n = 2 2 5})$ & Female $(\mathbf{n = 2 9 4})$ & P-Value \\
\hline Age (years) & $47.5 \pm 8.06$ & $46.7 \pm 7.93$ & 0.30 \\
\hline Gender & $225(43.3 \%)$ & $294(56.6 \%)$ & 0.09 \\
\hline Hemoglobin (g/dl) & $13.42 \pm 1.37$ & $11.5 \pm 1.07$ & 0.0001 \\
\hline Hematocrit (Hct.) (\%) & $43.0 \pm 6.07$ & $36.1 \pm 3.81$ & 0.0001 \\
\hline RBC counts (x10\%/ $/ \mathrm{L})$ & $3.5 \pm 1.31$ & $3.8 \pm 1.35$ & 0.09 \\
\hline MCV (fl) & $96.8 \pm 9.92$ & $105.5 \pm 12.04$ & 0.0001 \\
\hline MCH (pg) & $27.8 \pm 4.22$ & $30.1 \pm 3.67$ & 0.0001 \\
\hline MCHC (\%) & $34.3 \pm 2.14$ & $35.7 \pm 2.29$ & 0.0001 \\
\hline Cobalamin $(\mathrm{pg} / \mathrm{ml})$ & $245.3 \pm 63.0$ & $187.1 \pm 73.41$ & 0.0001 \\
\hline
\end{tabular}

\begin{tabular}{|c|c|c|c|}
\hline Vitamin $B_{12}$ categories & Mean & SD & P-Value \\
\hline Normal levels (>240 pg/ml) & 280.18 & 26.85 & \multirow{5}{*}{0.0001} \\
\hline Borderline deficiency (170-240 pg/dl) & 203.09 & 22.09 & \\
\hline Deficiency (<170 pg/dl) & 139.85 & 24.17 & \\
\hline Severe deficiency (<100 pg/dl) & 73.23 & 20.33 & \\
\hline Total & 212.34 & 74.82 & \\
\hline
\end{tabular}

Table-II. Cobalamin levels in study subjects $(n=300)$

\begin{tabular}{|l|c|c|c|c|}
\hline \multicolumn{1}{|c|}{ Category } & Male & Female & Total & P-Value \\
\hline Normal $(>240 \mathrm{pg} / \mathrm{ml})$ & 51 & 28 & 79 & \\
\hline Borderline $(170-240 \mathrm{pg} / \mathrm{dl})$ & 11 & 52 & 63 & 0.0001 \\
\hline Deficiency $(<170 \mathrm{pg} / \mathrm{dl})$ & 78 & 124 & 202 & 175 \\
\hline Severe deficiency $(<100 \mathrm{pg} / \mathrm{dl})$ & 85 & 90 & 519 & \\
\hline Total & 225 & 294 & \\
\hline
\end{tabular}

Table-III. Frequency of Cobalamin levels in study subjects $(n=519)$

Male $\square$ Female

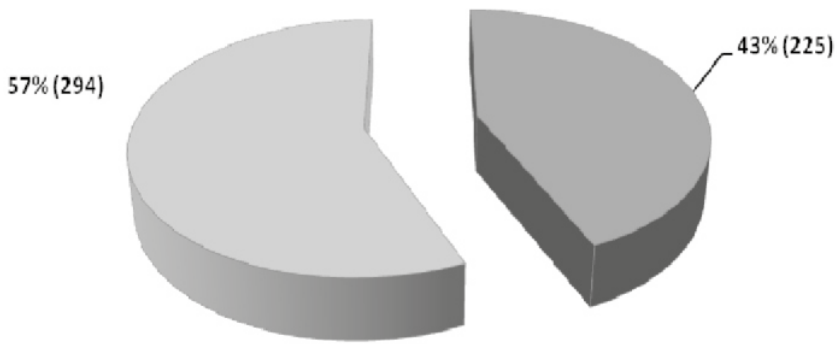

Figure-1. Frequency of male and female subjects
Cobalamin levels

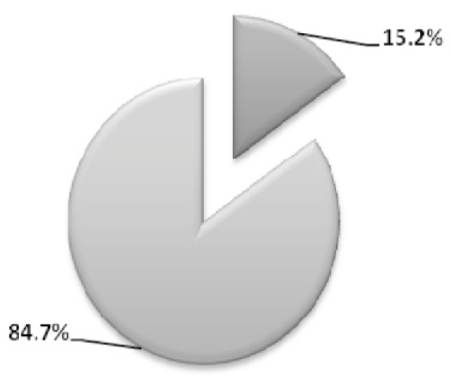

Normal Cobalamin

Any Cobabalin cefieincy 


\section{DISCUSSION}

The present is the first cross - sectional study from a tertiary care hospital that reports on the frequency of vitamin Cobalamin deficiency in macrocytic anemia reporting at our tertiary care hospital. The present study noted normal cobalamin in $15.2 \%(n=79)$ and any type of cobalamin deficiency was noted in $84.7 \%$ ( $n=$ 440) $(P=0.0001)$. The findings are consistent with recent studies from Pakistan. ${ }^{11-13}$ Frequency of Cobalamin deficiency is also consistent with previous studies. ${ }^{14,15}$ Of total 519 study subjects, the male and female comprised 225 (43.3\%) and $294(56.6 \%)$ respectively $(P=0.9)$. Male to female ratio was noted 1.30:1. Gender distribution of present study is in keeping with previous studies. ${ }^{16,17}$ Age (mean \pm SD) of male and female was $47.5 \pm 8.06$ and $46.7 \pm 7.93$ years respectively $(P=0.30)$. In present study, the age recognizes young study subjects. The findings corroborate with previous studies. ${ }^{15-17}$ In present study, normal cobalamin was noted in $15.2 \%(n=79)$ and any type of cobalamin deficiency was noted in $84.7 \%$ $(n=440) \quad(P=0.0001)$. Findings are consistent with recent studies reported from Pakistan. ${ }^{11-13}$

A previous study ${ }^{17}$ reported cobalamin deficiency of $72.6 \%$ that is inconsistent findings. The reason is sample size of previous study was low and different study populations. In present study, any type of cobalamin deficiency was noted in $84.7 \%$ $(n=440)(P=0.0001)$ (Figure-2) that is consistent with previous studies. ${ }^{18,19}$ In present study, only $15.2 \%(n=79)$ subjects show normal cobalamin $(>240 \mathrm{pg} / \mathrm{ml}$ ) levels that also corroborate with previous studies. ${ }^{17,20,21}$ In present study, the MCV in male was $96.8 \pm 9.92 \mathrm{fl}$ vs. $105.5 \pm 12.04 \mathrm{fl}$ in female $(P=0.0001)$ that shows raised values. Raised RBC - MCV points to the late nuclear maturation caused by cobalamin deficiency, because vitamin cobalamin is needed for the nucleotide (DNA) biosynthesis. Late nuclear maturation leads to elevated mean corpuscular volume (MCV). In present study the MCV was elevated in majority of subjects. MCV in male was $96.8 \pm 9.92 \mathrm{fl}$ vs. $105.5 \pm 12.04 \mathrm{fl}$ in female $(\mathrm{P}=0.0001)$. hypersegmented neutrophils being reliable clinic - hematological marker of cobalamin deficiency. Cobalamin deficiency of $85 \%$ and $78.5 \%$ has been reported in vegans and non - vegans. ${ }^{21}$ It is consistent with cobalamin deficiency of $84.7 \%$ of present study. However, other previous studies ${ }^{21-23}$ reported low frequency of cobalamin deficiency that is inconsistent findings. The $84.7 \%$ cobalamin deficiency of present study is a clinically important finding that must be reported for positive clinical outcome by doing cobalamin screening. Few limitations of the present study include $1^{\text {st. }}$ - sample size is small number, $2^{\text {nd }}$ :serum folate was not measured due to laboratory expense, and $3^{\text {rd }}$ :- sample size not representative of population of the study area. It is clear that the generalizability of findings is not possible for whole population and for other geographical countries.

\section{CONCLUSION}

The present study reports frequency of $84.7 \%$ Cobalamin deficiency in macrocytic anemia reporting at Isra University Hospital. Further studies are recommended by the treating physicians. Cobalamin screening programs be launched for its earlier deficiency detection particularly in anemic subjects. Cobalamin supplementation may prevent hematological complication.

Copyrigt $\odot 02$ June, 2020.

\section{REFERENCES}

1. Moore CA, Adil A. Macrocytic Anemia. In: Stat Pearls [Internet]. Treasure Island (FL): Stat Pearls Publishing 2020: 1 - 7 .

2. Agarwal P, Mital P, Meena VK, Mital P, Nawal CL, Goyal LK. A comparative study of levels of vitamin B12 in patients of type 2 diabetes mellitus on metformin and not on metformin at tertiary care center. Int $\mathrm{J} A d v$ Med 2016; 3:759-63.

3. Lanier JB, Park JJ, Callahan RC. Anemia in older adults. Am Fam Physician 2018; 98(7):437-442.

4. Khan MI, Waqar S. Sensitivity of mean corpuscular volume in detecting megaloblastic anemia. Pak $\mathrm{J}$ Pathol 2018; 29(2): 34-6.

5. Green AS, Chapuis N. A pernicious mean corpuscular volume. Blood Work Images Hematol 2018 131: 472.

Other previous studies ${ }^{16,17}$ reported the 
6. Momin M, Reddy KM, Prusty SK, Aluri A. Clinical, haematological and bone marrow aspiration evaluation in Megaloblastic anemia - study of $\mathbf{8 0}$ cases in a tertiary care hospital Telangana. Int $\mathrm{J}$ Curr Res Biol Med 2017; 2(8): 1-7.

7. Siddiqui B, Rabindranath D, Faridi SH, Khan A, Haiyat S, Eswaran R. Megaloblastic anemia: A common but often neglected cause of pyrexia of unknown origin. J TransI Int Med 2015; 3(2): 64-7.

8. Nagao T, Hirokawa M. Diagnosis and treatment of macrocytic anemias in adults. J Gen Fam Med 2017; 18(5):200-4.

9. Cheema A, Bramson J, Bajwa R, Hossain MA, Asir A. Hemolytic anemia an unusual presentation of Vitamin B12 Deficiency. J Hematol Thromb Dis 2018, $6: 1$.

10. Nizamani GS, Memon IA, Memon A, Khoharo HK. Vitamin B12 Deficiency with megaloblastic anemia: An Experience at Tertiary Care Hospital of Sindh. J Liaquat Uni Med Health Sci 2014; 13 (01): 13-17.

11. Rahman S, Sharif N, Rahman S, Suleman S, Gul A, Abbas M. Vitamin b12 deficiency among patients with megaloblastic anemia. J Med Sci 2019; 27: (2) 103106.

12. Kumar S, Shaikh A, Irshad Z, Kumari V, Parween S, Kashif $S$. Comparative study of mean corpuscular volume between lacto-vegetarian and non-vegetarian populations of tharparkar village. Ann Jinnah Sindh Med Uni 2019; 5(1): 21-25.

13. Jatoi S, Hafeez A, Riaz S, Riaz SU, Ali A, Ghauri MI, et al. Low Vitamin B12 Levels: An underestimated cause of minimal cognitive impairment and dementia. Cureus 12(2): e6976.

14. Khan A, Shafiq I, Hassan Shah M. Prevalence of Vitamin B12 deficiency in patients with Type II diabetes mellitus on metformin: A study from Khyber Pakhtunkhwa. Cureus 2017; 9(8):e1577.
15. Rauf A, Khan M, Arshad A. Frequency of Vitamin B12 deficiency in patients with Type 2 diabetes mellitus taking metformin. Pak J Med Health Sci 2015; 9 (4): 1316-8.

16. Ahmed S, Bogiatzi C, Hackam DG, Spence JD. Vitamin $B_{12}$ deficiency and hyperhomocysteinaemia in outpatients with stroke or transient ischemic attack: A cohort study at an academic medical centre. BMJ Open 2019; 9 (1):e026564.

17. Yasmeen T, Ali J, Khan K, Siddiqui N. Frequency and causes of anemia in Lymphoma patients. Pak J Med Sci 2019; 35(1):61-65.

18. Jabeen A, Mushtaq $\mathrm{S}$, Raza $\mathrm{H}$, Memon MA. Vitamin $\mathbf{B}_{12}$ deficiency: Prevalence and evaluation of a reversible co-morbidity in hypothyroid patients. Pak J Nucl Med 2016;6(1):25-31.

19. Sukumar N. Prevalence of vitamin $B_{12}$ insufficiency during pregnancy and its effect on offspring birth weight: A systematic review and meta-analysis. Am J Clin Nutr 2016; 103:1232-51.

20. Mazokopakis EE, Starakis IK. Recommendations for diagnosis and management of metformin induced vitamin B12 (Cbl) deficiency. Diabet Res Clin Pract 2012; 97(3):359-67.

21. Soofi S, Khan GN, Sadiq K, Ariff S, Habib A, Kureishy $S$, et al. Prevalence and possible factors associated with anaemia, and vitamin $B_{12}$ and folate deficiencies in women of reproductive age in Pakistan: analysis of national-level secondary survey data. BMJ Open 2017; 7:e018007.

22. Arora H, Srivastava N, Bala K. Prevalence of vitamin $B_{12}$ deficiency among urban populations complaining pain of lower limb and generalized weakness. Asian J Pharmac Clin Res 2016; 9 (3): 261-3.

23. Iqtidar $\mathrm{N}$, Chaudary MN. Misdiagnosed vitamin $\mathbf{B}_{12}$ deficiency: A challenge to be confronted by use of modern screening markers. J Pak Med Assoc 2012; 62 (11):1223-8. 


\section{AUTHORSHIP AND CONTRIBUTION DECLARATION}

\begin{tabular}{|c|c|c|c|}
\hline Sr. \# & Author(s) Full Name & Contribution to the paper & Author(s) Signature \\
\hline 1 & Kashif Rasheed Shaikh & $\begin{array}{l}\text { Conception, materials handling, } \\
\text { Collection of materials, compilation of } \\
\text { resutls, statistical analysis, manuscript } \\
\text { write up, correspondence. }\end{array}$ & $k$ \\
\hline 2 & Shumaila Shaikh & $\begin{array}{l}\text { Materials handling, compilation of } \\
\text { resutls, statistical analysis, Manuscript } \\
\text { write up, Proof reading. }\end{array}$ & \\
\hline 3 & Sadia Tabassum & $\begin{array}{l}\text { Conception materials handling, } \\
\text { Interpretation lab investigations, } \\
\text { Manuscript write up, Proof reading. } \\
\text { Literature review, Concept, Materials }\end{array}$ & Changs \\
\hline 4 & Shagufta Memon & $\begin{array}{l}\text { Literature review, Concept, Materials } \\
\text { handling, Interpretation lab } \\
\text { investigations, Manuscript write up, } \\
\text { Proof reading. }\end{array}$ & Q \\
\hline 5 & Umair Ali Soomro & $\begin{array}{l}\text { Interpretation lab investigations, } \\
\text { manuscript write up, Proof reading. }\end{array}$ & \\
\hline 6 & Shomail Saeed Siddiqui & Concept, Materials handling, & \\
\hline 7 & Haji Khan Khoharo & $\begin{array}{l}\text { Collection of materials, Compilation } \\
\text { of results, Statistical analysis, } \\
\text { Manuscript write. } \\
\text { Interpretation lab investigation, } \\
\text { Manuscript write up, Proof reading. }\end{array}$ & taiplet \\
\hline
\end{tabular}

